\title{
Exploring motivations to change; change the state or change the value
}

\author{
$\underline{\text { T. Lynam }}{ }^{\mathrm{a}}$ J.L. Langridge ${ }^{\mathrm{a}}$ \\ ${ }^{a}$ CSIRO, Climate Adaptation Flagship. Email: tim.lynam@csiro.au
}

\begin{abstract}
We use cognitive dissonance theory to frame the presentation of results on how dissatisfaction with employment opportunities (dissonance) leads to education change and hence employment change. We discuss these results and discuss the theory in relation to modelling human adaptation to climate change.
\end{abstract}

Consistent with cognitive dissonance theory we predict that when people are dissatisfied with the state of something that is important to them they seek to change either (1) the state, or; (2) the value they associate with that state. If, for example, people are dissatisfied with their employment state then we predict they would move to change (improve) it. If they are unable to change their employment state then they may well change their attitude to this factor in their lives and be more accepting and hence satisfied with the state of their employment. They would construct a narrative around why employment is not that important.

We use survey data collected over 8 years to test our predictions that when faced with an unsatisfactory state people would first try and change the state and if this failed they would change their attitude towards the state. We found that moderate dissatisfaction was more likely than not to lead to changes in education and thence employment satisfaction. Contrary to our expectations people who were very dissatisfied with their employment opportunities were unlikely to change their education status. However, people that did not change their education ended up with improved employment satisfaction in 2009/2010 as cognitive dissonance might predict.

We discuss the results in relation to recent developments in cognitive dissonance theory which suggest that dissonance is likely to be highly relevant in action oriented situations. We suggest that simple and targeted statistical analyses such as those we present may be useful in modelling to explore human responses to climate change in the context of policy evaluation.

Keywords: employment, satisfaction, education, cognitive dissonance 


\section{INTRODUCTION}

In seeking to understand, explain or predict human behavioural responses to climate change cognitive dissonance may be an important factor (Anable 2006, Line 2008, Lorenzoni, Nicholsoncole and Whitmarsh 2007). Cognitive dissonance theory (Festinger 1957, Aronson 1969) posits that when a person holds inconsistent cognitions (beliefs, attitudes, ideas, opinions) such as "I am really unhappy in my job" and "I will not try and find another one", these will give rise to mental discomfort which the person will seek to reduce (Tavris and Aronson, 2008). Dissonance has been shown to be a strong motivator of human attitudes and behaviour across a number of areas(Osbaldiston and Schott 2011, Cummings and Venkatesan 1976, Harmon-Jones 2001, James and Gutkind 1985, Kantola, Syme and Campbell 1984, Ghapanchi and Aurum 2011). It can motivate change in the physical dimensions of life such as taking steps to improve ones education in order to improve ones employment and so reduce dissonance. It can reduce dissonance through motivating changes in how we feel about our employment opportunities. Or it can motivate both changes in behaviour or cognitions. Options for reducing the discomfort boil down to changing one of the cognitions; in the example of job satisfaction just outlined, the person must either change their job or change their satisfaction with their current job. Given that individual reponses to climate change may require significant behavioural change we might expect a good deal of cognitive dissonance as individuals recognise the need to change their behaviour whilst at the same time not wishing to change their quality of life (Lorenzoni et al. 2007).

What does the theory of cognitive dissonance mean for our ability to model, in a predictive sense, human adaptation to climate change? Consistent with the predictions of cognitive dissonance theory dissatisfaction is a measure of dissonance and is likely to result in behaviours to change the associated cognitions. Among the many studies involving cognitive dissonance, measures of dissatisfaction have been strongly correlated with cognitive dissonancein consumer behaviour studies (Sweeney, Soutar and Johnson 1996), in addressing the connection between body image satisfaction and some eating disorders (Luethcke, McDaniel and Becker 2011), and as an important determinant of employee turnover or functioning (Ghapanchi and Aurum 2011, Miller et al. 2000). Employment opportunities are an important component of human well being (WHA 2005, Baxter et al. 2007) and are likely to be notably impacted by climate change, particularly in terms of their spatial distribution but also sectoral employment opportunities as energy intensive and labour intensive industries are compelled to change (Dupressoir et al. 2005, GHK 2009). In this paper we use secondary data on satisfaction with employment opportunities to explore what cognitive dissonance might mean for modelling human responses to climate change. The data do not permit us to examine climate change employment satisfaction relations directly. Our purpose is more to use a readily available data set to explore the implications of cognitive dissonance theory for modelling human behaviour; were data available on aspects of human behaviour in relation to climate change we suspect the same general issues surrounding cognitive dissonance would be pertinent. We use employment data as being indicative of the types of social processes that will need to be changed in order to address climate change.

Cognitive dissonance theory suggests the following hytpothesis can be tested in relation to employment satisfaction: Low satisfaction with employment opportunities indicates dissonance. Individuals experiencing this dissonance will address it either through improving employment opportunities (in our case through improving education) or altering their employment satisfaction state. They must thus either change their employment state or improve their satisfaction to reduce dissonance.

In the next section of the paper we describe the data and methods that we have used to explore cognitive dissonance in relation to employment satisfaction. We present results in relation to five key questions:

1) Does employment satisfaction improve with employment state?

2) Does the probability of being in full or part time employment increase with greater education?

3) Does low employment satisfaction increase the likelihood of improved educational state?

4) Does improved education increase the likelihood of improved employment state?

5) Does employment satisfaction increase without change in employment state?

We conclude with making observations on the implications of these results for modelling human responses to climate change.

\section{METHODS AND DATA}

The data used to to explore peoples change in satisfaction with employment were a subset of that collected as part of the Household, Income and Labour Dynamics in Australia survey (Watson, 2010 and http://www.melbourneinstitute.com/hilda). The data consisted of 9 survey waves beginning in October 2002 
ending with with the most recent in June 2010, totalling 116685 respondent records representative of 20452 individuals.

For our analyses we used data from the HILDA surveys for individuals surveyed in the first or second waves and who were also surveyed in the eighth or ninth waves. We calculated a change statistic for satisfaction, employment status and education where we compared individuals recorded in waves 8 or 9 with those surveyed in waves 1 or 2 . Change in education state was coded as the numerical difference in the reported education level between wave 8 or 9 and wave 1 or 2 . Where any increase in the education state occurred between wave 1 or 2 and waves 8 or 9 this was coded as a change in education. Change in employment opportunities satisfaction was coded as the numerical difference between the satisfaction scores assigned by individuals in wave 8 or 9 and the scores they gave in waves 1 or 2 . Respondents in wave 1 or 2 that reported employment satisfaction scores of 0 to 3 were coded as very dissatisfied, those with reported scores of 4 to 7 were coded as moderately satisfied / dissatisfied and those with scores greater than 7 were coded as very satisfied. Respondents whose employment status improved $(1>2>3>4)$ from waves 1 or 2 to waves 8 or 9 were coded as having improved employment, those whose employment status got worse $(4<3<2<1)$ were coded as having worse employment and others were coded as having no change.

Cross tabulation results were carried out in $\mathrm{R}$ (version 2.13) using the CrossTable analysis in the gmodels package. Statistical results are presented as adjusted standard residuals. Absolute values for adjusted standard residuals $>3.09$ made a signficant contribution to the $\mathrm{Chi}^{2}$ value at $\mathrm{p}<0.001$; adjusted standard residual values between 2.33 and 3.09 made a signficant contribution to the $\mathrm{Chi}^{2}$ value at $\mathrm{p}<0.01$; and adjusted standard residual values between 1.64 and 2.33 made a signficant contribution to the Chi ${ }^{2}$ value at $\mathrm{p}<0.05$. The $\mathrm{N}$ values in each table reflect the number of instances of complete data (i.e. no missing values) in the data set used (individuals that were in either or both waves 1 or 2 and waves 8 or 9).

\section{RESULTS}

Prior to testing the hypothesis posed in the introductory section we present results designed to test some of the assumptions we need to make. In particular that employment satisfaction improves with employment status (full time $>$ part time $>$ unemployed); that higher education improves the likelihood of employment in the higher states (i.e. greater education is more likely to result in full or part time employment); and education improvement results in improved employment state.

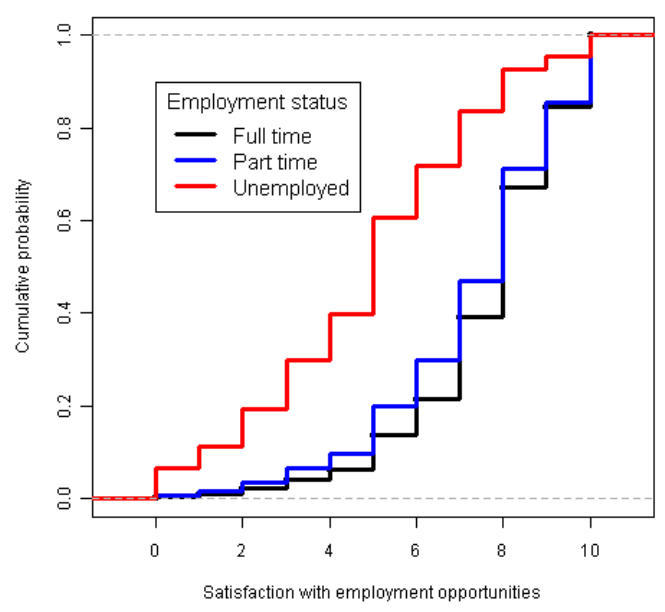

3.1. Employment satisfaction improves with employment stateFull time employed people (across gender and age classes) were more likely to be highly satisfied with their employment opportunities than were part time or unemployed people (Error! Reference source not found.). Part time employees were more likely to be moderately satisfied with their employment opportunities and unemployed people were more likely to be moderately to highly dissatisfied with their employment opportunities.

\subsection{Employment state improves with education}

Overall there was a significant relationship between employment state and education level (Pearson's Chisquared test: $\mathrm{Chi}^{2}=4206.96$, d.f. $\left.=16, \mathrm{p}<0.001\right)$. People with higher education had a higher probability of being full time or part time employed than did people with lower education (Error! Reference source not found.). People with graduate degrees through to those with Cert III or IV education were far more likely to
Figure 1. Cumulative probability of satisfaction with employment opportunities by employment status. The further to the right a curve is the greater the level of satisfaction. 
be in full time employment, whilst those with school certificates (Year 11, and 12) or Cert II were more likely to be part time employed or unemployed. Part time and unemployed people were far more likely to have lower education levels than were those with higher education levels.

\subsection{Low employment satisfaction leads to education change}

There was a highly significant relationship between employment satisfaction and employment change (Pearson's Chi-squared test: $\mathrm{Chi}^{2}=$ 25.79 , d.f. $=2, \mathrm{p}<0.001)$. Surprisingly people that were very dissatisfied with their employment opportunities in either wave 1 or wave 2 were unlikely to change their education status (Table 1). People that were moderately dissatisfied or moderately satisfied were highly likely to change their education state. The data on people that were very satisfied with their employment opportunities did not contribute to the overall Chi square value.

\subsection{Improved education leads to improved employment}

Improved education was significantly related to changes in

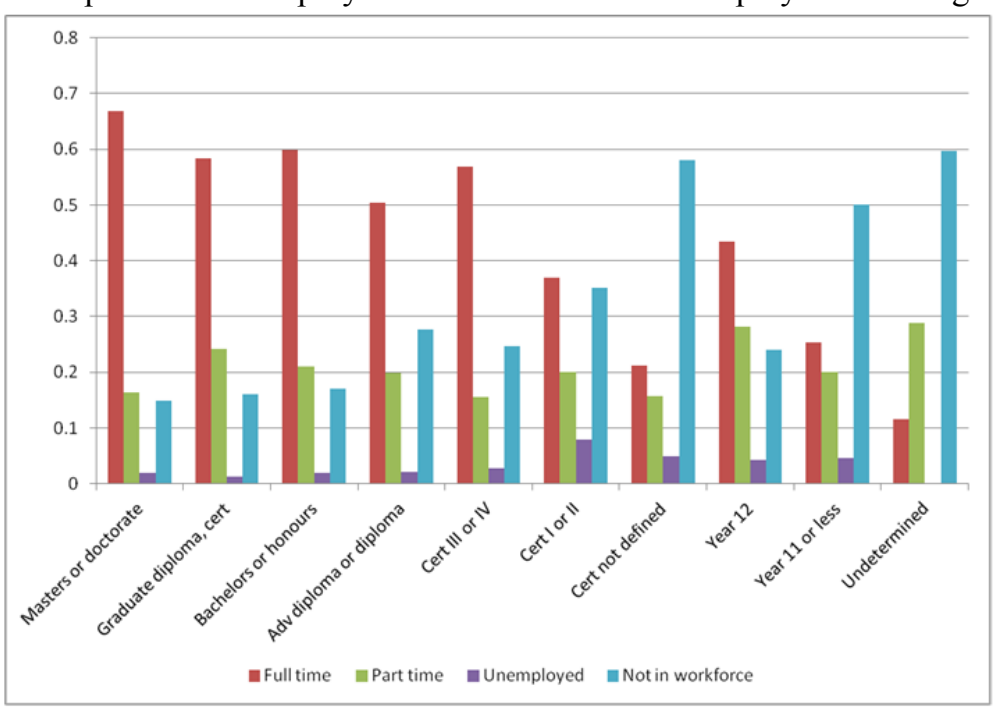

Figure 2. Probability of being in a given employment state with different educational levels. Source: HILDA. N=116,685. employment state (Pearson's Chisquared test: $\mathrm{Chi}^{2}=25.79141$, d.f. $\left.=2, \mathrm{p}<0.001\right)$. Those who improved their education state between wave 1 or 2 and waves 8 or 9 were far more likely to have an improved employment state in wave eight or nine than those whose education remained unchanged. Those whose education remained unchanged over the period were more likely to have no change in their employment state or their employment state would have

Table 1. Cross tabulation results for employment satisfaction in wave 1 or 2 by change in education level over the eight year period between wave 1 and 9 . Source: HILDA, waves 1 through 9, $\mathrm{N}=14,176$. Significance of adjusted residual contributions to $\mathrm{Chi}^{2}$ : boldface, $\mathrm{p}<0.001$.

\begin{tabular}{|c|c|c|c|c|}
\hline $\begin{array}{l}\text { Employment } \\
\text { satisfaction }\end{array}$ & Statistic & $\begin{array}{l}\text { Changed } \\
\text { Education }\end{array}$ & $\begin{array}{c}\text { No education } \\
\text { change }\end{array}$ & Row total \\
\hline \multirow[t]{2}{*}{ Very dissatisfied } & Actual (expected) $\mathrm{N}$ & $263(335.7)$ & $1617(1544.3)$ & 1880 \\
\hline & Adjusted standard residuals & -4.698 & 4.698 & \\
\hline \multirow[t]{2}{*}{ Moderate } & Actual (expected) $\mathrm{N}$ & $1179(1101.6)$ & $4991(5068.4)$ & 6170 \\
\hline & Adjusted standard residuals & 3.424 & -3.424 & \\
\hline \multirow[t]{3}{*}{ Very satisfied } & Actual (expected) $\mathrm{N}$ & $1089(1093.7)$ & $5037(5032.3)$ & 6126 \\
\hline & Adjusted standard residuals & -0.21 & 0.21 & \\
\hline & Column total & 2531 & 11645 & 14176 \\
\hline
\end{tabular}

got worse.

\subsection{Satisfaction improves through time for those who do not improve employment state}

For those who did not change their employment state between waves 1 or 2 and waves 8 or 9 and did not improve their education there was a strong and significant relationship between initial employment satisfaction state and change in satisfaction state (Pearson's Chi-squared test: $\mathrm{Chi}^{2}=1853.332$, d.f. $=4, \mathrm{p}<$ $0.001)$. Respondents who started out in wave 1 or 2 being highly dissatisfied $(<=4)$ or neutral to slightly 
satisfied (5 to 7) with their employment opportunities and did not change their employment state or education level through to wave 8 or 9 , were more likely to have a positive change in their satisfaction state than they

Table 2. Cross tabulation results for change in employment satisfaction state between wave 1 or 2 and 8 or 9 by initial employment satisfaction state for those who did not change their employment state and did not change their education state. Source: HILDA, waves 1 through 9, $N=1794$. Significance of adjusted residual contributions to $\mathrm{Chi}^{2}$ : boldface, $\mathrm{p}<0.001$.

\begin{tabular}{|c|c|c|c|c|c|}
\hline \multirow{2}{*}{$\begin{array}{c}\text { Initial satisfaction } \\
\text { state }\end{array}$} & \multirow[b]{2}{*}{ Statistic } & \multicolumn{3}{|c|}{ Change in satisfaction state } & \multirow{2}{*}{$\begin{array}{l}\text { Row } \\
\text { total }\end{array}$} \\
\hline & & Positive & No change & Negative & \\
\hline \multirow[t]{2}{*}{ Dissatisfied } & Actual (expected) $\mathrm{N}$ & $354(239.6)$ & $76(111.7)$ & $46(124.7)$ & 476 \\
\hline & Adjusted standard residuals & 12.2 & -4.5 & -9.6 & \\
\hline \multirow[t]{2}{*}{ Neutral } & Actual (expected) $\mathrm{N}$ & $329(221)$ & $54(103)$ & $56(115)$ & 439 \\
\hline & Adjusted standard residuals & 11.9 & -6.4 & -7.4 & \\
\hline \multirow[t]{3}{*}{ Satisfied } & Actual (expected) $\mathrm{N}$ & $220(442.4)$ & $291(206.3)$ & $368(230.3)$ & 879 \\
\hline & Adjusted standard residuals & -21 & 9.4 & 14.8 & \\
\hline & Column total & 903 & 421 & 470 & 1794 \\
\hline Pearson's Chi-square & test & $\mathrm{Chi}^{2}=451.1258$ & d.f. $=4 \quad p<$ & & \\
\hline
\end{tabular}

were to have either no change or a negative change in their satisfaction state (Table 2). This result supports our prediction that those who do not improve their employment status reduce their dissonance through altering their level of satisfaction; in essence increasing their satisfaction with their employment opportunities.

\section{DISCUSSION}

We started off by demonstrating that employment satisfaction improved with employment state; those who were full-time or part-time employed were found to be more satisfied with their employment opportunities than those who were unemployed. We also demonstrated that respondents who had higher educational qualifications were more likely to be full or part-time employed and less likely to be unemployed than those with lower educational qualifications. Thus better education is associated with better employment status.

With these assumptions tested we presented results that demonstrated the application of cognitive dissonance theory to the analysis of employment satisfaction and employment change. Firstly we demonstrated that people who were moderately dissatisfied or moderately satisfied with their employment state were more likely to improve their education state than those who were either very dissatisfied or very satisfied with their employment state. These results were partially consistent with what cognitive dissonance theory predicts; the theory suggests that the greater the dissonance the greater the motivation to change one of the cognitions. Usually the cognition least resistant to change would be modified (Harmon-Jones and Harmon-Jones 2008, Beckmann and Irle 1985). We expected therefore that the greater the dissatisfaction the greater the motivation to alter either the employment state or the satisfaction with employment opportunities. Our model expectations were not supported by the data from the very dissatisfied cohort. We thus examined this cohort more closely and found that they were dissatisfied with their employment opportunities irresepective of improved education or employment.

We then tested the prediction that those who did not improve their employment state would increase their level of satisfaction with their employment opportunities. The data show that people that started out very dissatisfied and did not change their employment state were likely to become more satisfied through time, consistent with the predictions of dissonance theory.

To move beyond statistical description of patterns of the consequences of cognitive dissonance requires that we model the processes that give rise to dissonance as well as the behavioural (including cognitive change) consequences. New developments in cognitive dissonance theory suggest that dissonance reduction evolved to facilitate action; if people were to get locked into discrepant cognitions this might inhibit action. Dissonance reduction is therefore important to ensure action (Beckmann and Irle 1985; Harmon-Jones and Harmon-Jones 2008). Different phases in action sequences have been shown to reflect different cognitive tendencies and hence cognitive dissonance plays out in different ways in these different phases (Gollwitzer 
1990; Gollwitzer and Bayer 1999). Gollwitzer (1990) identified four phases of action: the predecisional phase characterised by wishing and deliberating; the decisional and preactional phase in which decisions and plans to achieve the action goal are made; the action initiation and action phase in which the action is initiated and carried out; and the final phase is the evaluative phase in which goal achievement is evaluated. Gollwitzer (Gollwitzer 1990; Gollwitzer and Bayer 1999) identified mind-sets (orientations) associated with each of the action phases and highlighted the differential information processing tasks associated with each mind-set. Gollwitzer and Bayer (1999,p419) tested the cognitive processing predictions of their model for the deliberative and implemental mind-sets and found that "People in a deliberative mindset are found to be open-minded with respect to available information, to be tuned toward feasibility-related and desirabilityrelated information, to analyze feasibility-related information accurately, and to analyze desirability-related information impartially.... Finally, it hampers action initiation and persistence in behavioural conflict situations." In contrast "People in an implemental mindset are found to be closed-minded to available information, to be tuned toward implementation-related information, to analyze feasibility-related information in an overly positive manner, and to analyze desirability-related information in a partial manner." Thus cognitive dissonance is likely to be highly important in the implemental phase (and mind-set), a finding supported by experimental work reported by Beckmann in relation to action orientations (Beckmann and Irle 1985).

Our discussion in relation to cognitive dissonance theory and its implications for modelling human behaviour spans a very large body of research and as such is by necessity simplistic and limited. There is much that we have not explored in relation to the application of cognitive dissonance theory to modelling human adaptation to climate change. Many of the experimental results we have used for example relate to human responses occurring over a brief period of time and there was seldom much follow-up to identify the sustainability of the changes. We suspect that effective policy evaluation modelling would need to embed action oriented dissonance modelling in models of large-scale social change such as the trans-theoretical model of change (Prochaska and DiClemente 1986, Prochaska, DiClemente and Norcross 1992, Prochaska et al. 1988) in which different processes give rise to awareness for the need, plan to enact, and process to maintain changes in human behaviour. Many of these models of social change assume supportive social conditions, such as supportive social networks or help services (Oldenberg, Glanz and Ffrench 1999) and hence impose an additional requirement on modelling to predict the availability of such conditions. We have also not presented differences across age and gender groups in this paper other than making very brief mention of patterns that were evident.

\section{CONCLUSIONS}

Cognitive dissonance theory poses a number of challenges for modelling human behaviour in relation to climate change: Firstly, where do the norms for job satisfaction come from? The norms that people are likely to use in cognitions of value states (such as employment satisfaction) are likely to be derived from social interactions or comparisons among peers. We therefore we need to either make these exogenous to the modelling process (and hence hold relatively constant) or model them. Modelling them would require a complex and creative understanding of norm creation and maintenance. A second challenge that dissonance theory poses is the need to model multiple cognitions within any individual in relation to the issues of concern and to identify within the modelling which cognitions are likely to be most resistant to change, which get changed and thence the behavioural outcomes of dissonance reduction. None of these are likely to be easy and all are social in the sense of involving social interactions as much as the characteristics of the modelled individual. A third challenge is the need to model social processes, in the sense of the transtheoretical model of change, that are required to support significant behavioural change. This again points to a very social modelling approach where actors within the model engage in meaningful social interaction. All of these processes point at models of creativity; we cannot a priori define what will emerge, it has to emerge from the models. We do not as yet have good modelling paradigms for these sorts of processes.

It may be that we have to use people themselves as the creative element in modelling human adaptations to climate change; use computer simulation models for what they are good at (rapidly combining variable and parameter states of pre-existing variables) in combination with people doing what they are good at (being creative). At this stage of our modelling abilities perhaps the best we can do in modelling human responses to phenomenon such as climate change is keep real peole in the models through having them interact with models, model outputs or modellers in ways that are meaningfully interpreted by all parties.

\section{ACKNOWLEDGEMENTS}

We are grateful for the support of the CSIRO's Climate Adaptation Flagship, Pathways to Adaptation theme. The paper was greatly improved with comments from Sorada Tapuswan and Kirsty Kitto. 


\section{REFERENCES}

Anable, J. L., B Kelay, T. 2006. An evidence base review of public attitudes to climate change and transport behaviour. UK: THE DEPARTMENT FOR TRANSPORT.

Aronson, E. 1969. The theory of cognitive dissonance: A current perspective. In Advances in Experimental Social Psychology, ed. L. Berkowitz, 1-34. New York: Academic Press.

Baxter, J., M. Gray, M. Alexander, L. Strazdins \& M. Bittman. 2007. Mothers and fathers with young children: paid employment, caring and well being. In Social Policy Research paper. Australian institute of Family Studies.

Beckmann, J. \& M. Irle. 1985. Dissonance and action control. In Action control: From cognition to behavior, eds. J. Kuhl \& J. Beckmann, 129-150. Berlin: Springer-Verlag.

Cummings, W. H. \& M. Venkatesan (1976) Cognitive dissonance and consumer behavior: A review of the evidence. JMR, Journal of Marketing Research (pre-1986), 13, 303-303.

Dupressoir, S., A. B. Sanchez, P. Nussbaumer, J. Riechmann, P. Bobe, D. Dubois, C. Duchesne, A. Mestre, J. Monplet, P. Morvannou, J.-F. Poupard, H. Robert, M. Tagzout, V. Höfele, W. Irrek, L. Jarczynski, D. Koth, M. Prantner, F. Rudolph, C. Schäfer-Sparenberg, S. Thomas \& O. Wagner. 2005. Climate change and employment. Impact on employment in the European Union-25 of climate change and $\mathrm{CO} 2$ emission reduction measures by 2030. European Trade Union Confederation (ETUC), Instituto Sindical de Trabajo, Ambiente y Salud (ISTAS), Social Development Agency (SDA), Syndex, Wuppertal Institute.

Festinger, L. 1957. A theory of cognitive dissonance. Stanford, CA: Stanford University Press.

Ghapanchi, A. H. \& A. Aurum (2011) Antecedents to IT personnel's intentions to leave: A systematic literature review. The Journal of Systems and Software, 84, 238-249.

GHK. 2009. The Impacts of Climate Change on European Employment and Skills in the Short to MediumTerm: A Review of the Literature. Final Report. 47.

Harmon-Jones, E. 2001. The role of affect in cognitive-dissonance processes. In Handbook of affect and social cognition, ed. J. Forgas, 237-254. Mahwah, NJ: Lawrence Erlbaum.

Harmon-Jones, E. \& C. Harmon-Jones (2008) Action-Based Model of Dissonance: A Review of Behavioral, Anterior Cingulate, and Prefrontal Cortical Mechanisms. Social and Personality Psychology Compass, 2, 1518-1538.

James, J. \& E. Gutkind (1985) Attitude Change Revisited: Cognitive Dissonance Theory and Development Policy. World Development, 13, 1139-1139-1149.

Kantola, S. J., G. J. Syme \& N. A. Campbell (1984) Cognitive dissonance and energy conservation. Journal of Applied Psychology, 69, 416-421.

Line, T. 2008. The attitudes of young people towards transport in the context of climate change. In Faculty of the Built Environment, 363. University of the West of England.

Lorenzoni, I., S. Nicholsoncole \& L. Whitmarsh (2007) Barriers perceived to engaging with climate change among the UK public and their policy implications. Global Environmental Change, 17, 445-459.

Luethcke, C. A., L. McDaniel \& C. Becker. 2011. A comparison of mindfulness, nonjudgemental, and cognitive dissonance-based approaches to mirror exposure. In Psychology Faculty Research. Trinity University.

Miller, D. I., N. Verhoek-Miller, M. Giesen \& E. Wells-Parker (2000) Some empirical evidence for ecological dissonance theory. Psychological Report, 86, 415-420.

Oldenberg, B., K. Glanz \& M. Ffrench (1999) The application of staging models to the understanding of health behaviour change and the promotion of health. Psychology and Health, 14, 503-516.

Osbaldiston, R. \& J. P. Schott (2011) Environmental Sustainability and Behavioral Science: Meta-Analysis of Proenvironmental Behavior Experiments. Environment and Behavior.

Prochaska, J. \& C. DiClemente. 1986. Toward a comprehensive model of change. In Treating addictive behaviors: processes of change, eds. W. Miller \& N. Heather. New York: Plenum Press.

Prochaska, J., C. DiClemente \& J. Norcross (1992) In search of how people change applications to addictive behaviors. Am Psychol, 47, 1102-1114.

Prochaska, J. O., W. F. Velicer, C. C. DiClemente \& J. Fava (1988) Measuring Processes of Change: Applications to the Cessation of Smoking. Journal of Consulting and Clinical Psychology, 56, 520528.

Sweeney, J. C., G. N. Soutar \& L. W. Johnson (1996) Are satisfaction and dissonance the same construct? A preliminary analysis. Journal of Consumer Satisfaction, Dissatisfaction and Complaining Behavior, 9, 138-143.

WHA. 2005. Paid work and women's health. Women's Health Australia. 